\title{
Rancang Bangun Aplikasi "Sipedi” Pada UPTD Puskesmas Nanggulan Kulon Progo
}

\author{
Budi Kristianto ${ }^{1}$, Elly Muningsih ${ }^{2}$ \\ 1,2 Universitas Bina Sarana Informatika \\ 1budzdiii@gmail.com, ${ }^{2}$ elly.emh@bsi.ac.id
}

\begin{abstract}
The existence of the Puskesmas Library under the management of the Nanggulan Puskesmas UPTD apart from being a community service is also a source of data, information and knowledge. Web-based Digital Library is very necessary because it can facilitate the storage and dissemination of information and knowledge to the entire community. For this research, the design of the "Sipedi" application is a web-based Digital Library Information System at UPTD Puskesmas Nanggulan. Data collection methods used were interviews, observation, and literature study. This website was developed using a PHP program and data processing using a MySQL database. Display design was designed using Adobe Dreamweaver CS6. This research software development method uses a waterfall model with several stages, including software requirements analysis, design, program code creation, testing, and support (maintenance). While testing is done using Black Box Testing.
\end{abstract}

Keywords : digital library, Sipedi, waterfall model, black box testing

\begin{abstract}
Abstrak : Keberadaan Perpustakaan Puskesmas dibawah pengelolaan UPTD Puskesmas Nanggulan selain sebagai layanan masyarakat juga merupakan sumber data, informasi, dan pengetahuan. Perpustakaan Digital berbasis Web sangat diperlukan karena dapat mempermudah penyimpanan dan penyebarluasan informasi serta ilmu pengetahuan ke seluruh masyarakat. Untuk penelitian ini merancang bangun aplikasi "Sipedi" yaitu Sistem Informasi Perpustakaan Digital berbasis web pada UPTD Puskesmas Nanggulan. Metode pengumpulan data yang digunakan adalah wawancara, observasi, dan studi pustaka. Website ini dikembangkan menggunakan program PHP dan pengolahan data menggunakan database MySQL. Design tampilan dirancang menggunakan Adobe Dreamweaver CS6. Metode pengembangan perangkat lunak penelitian ini menggunakan model waterfall dengan beberapa tahapan, meliputi analisis kebutuhan perangkat lunak, desain, pembuatan kode program, pengujian, dan pendukung (support) atau pemeliharaan (maintenance). Sedangkan pengujian yang dilakukan menggunakan Black Box Testing.
\end{abstract}

Kata kunci : perpustakaan digital, Sipedi, model waterfall, black box testing

(1) $\$$ This is an open access article distributed under the Creative Commons Attribution License, which permits unrestricted use, distribution, and reproduction in any medium, provided the original work is properly cited. (02019 by author and IJSE-Indonesian Journal on Software Engineering.

\section{A. PENDAhUluan}

Perpustakaan di Yogyakarta saat ini masih belum menjangkau ke seluruh masyarakat. Jumlah penduduk D.I. Yogyakarta pada tahun 2015 ada 3.679.179 jiwa (Badan Pusat Statistik, 2016). Jumlah perpustakaan menurut jenisnya pada tahun 2015 ada 3.461 perpustakaan. Dari jumlah seluruh perpustakaan yang ada perpustakaan yang berjenis internet ada 64 perpustakaan atau hanya sebesar 1,85\% (Badan Pusat Statistik, 2016). Dijelaskan bahwa "Perpustakaan Khusus adalah perpustakaan yang diselenggarakan oleh lembaga atau instansi Negara, pemerintah, pemerintah daerah ataupun lembaga atau instansi swasta yang layanannya diperuntukkan bagi pengguna di lingkungan lembaga atau instansi yang bersangkutan" (Hasugian, 2009). Perpustakaan yang ada di Puskesmas termasuk dalam Perpustakaan Khusus. Permenkes No 75 Th 2014 tentang Pusat Kesehatan Masyarakat menyebutkan bahwa "Pusat Kesehatan Masyarakat yang selanjutnya disebut Puskesmas adalah fasilitas pelayanan kesehatan yang menyelenggarakan upaya kesehatan masyarakat dan upaya kesehatan perseorangan tingkat pertama, dengan lebih mengutamakan upaya 
promotif dan preventif, untuk mencapai derajat kesehatan masyarakat yang setinggi-tingginya di wilayah kerjanya". Unit Pelaksana Teknis Daerah (UPTD) Puskesmas Nanggulan Kulon Progo adalah Fasilitas Kesehatan Tingkat Pertama (FKTP) yang bertanggung jawab di wilayah kerja Kecamatan Nanggulan Kabupaten Kulon Progo. Sarana pendukung bagi Puskesmas dalam meningkatkan pengetahuan dan kemandirian masyarakat dalam kesehatan adalah dengan adanya Perpustakaan Puskesmas. Keberadaan Perpustakaan Puskesmas di bawah pengelolaan dari UPTD Puskesmas selain sebagai layanan masyarakat juga merupakan sumber data, informasi, dan pengetahuan. Perpustakaan Digital atau digital library menawarkan memudahkan bagi pengguna untuk mengakses sumber-sumber elektronik pada waktu dan kesempatan terbatas tanpa harus terikat kepada jam buka perpustakaan (Saleh, 2010). Perpustakaan digital membuat pengguna bisa menikmati layanan sepuasnya, kapanpun, dan dimanapun. Akses perpustakaan digital lebih mudah dibanding dengan perpustakaan konvensional. Di era teknologi informasi sekarang Perpustakaan Digital berbasis Web sangat diperlukan karena dapat mempermudah penyimpanan dan penyebarluasan informasi serta ilmu pengetahuan ke seluruh masyarakat. Perpustakaan Digital Berbasis Web dapat diakses dimana saja dan kapan saja. Atas dasar identifikasi masalah yang telah dipaparkan di atas, penelitian ini bertujuan untuk merancang dan membangun aplikasi "Sipedi" yaitu Sistem Informasi Perpustakaan Digital berbasis Web pada Puskesmas untuk mempermudah penyimpanan dan penyebarluasan informasi serta ilmu pengetahuan di bidang kesehatan ke seluruh masyarakat.

\section{B. TINJAUAN PUSTAKA}

\section{Website}

Website merupakan kumpulan halaman-halaman web yang terdapat dari sebuah domain yang mengandung informasi (Yuhefizar, 2013). Sebuah website dibangun atas banyak halaman web yang saling berhubungan satu sama lainnya. Hubungan antara satu halaman web yang lainnya disebut dengan Hyperlink sedangkan teks yang dijadikan media penghubung disebut Hypertext. Website menyajikan sistem informasi dalam bentuk teks, gambar, video, dan file-file digital yang tersimpan dalam bentuk hypertext. Web diakses menggunakan softwareclient web yang disebut browser yang berguna untuk membaca halaman web yang sudah tersimpan di server web melalui protocol yang disebut HTTP (Hypertext Transfer Protocol) (Simarmata, 2010). Secara garis besar, website bisa digolongkan menjadi tiga yaitu website statis, website dinamis dan website interaktif. Website statis adalah web yang mempunyai halamannya tidak berubah atau tetap. Jika ingin diubah, maka dilakukan secara manual dengan mengubah kode menjadi struktur dari website tersebut. Website dinamis merupakan website yang melakukan update sesering mungkin. Contoh website dinamis adalah web berita atau web portal. Website interaktif adalah web yang memungkinkan user untuk berdiskusi didalam forum. Biasanya website ini memiliki moderator agar perbincangan tidak keluar dari topik pembahasan yang sedang dibahas (Puspitosari, 2010).

\section{Web Browser}

Web browser adalah suatu aplikasi perangkat lunak yang bisa digunakan untuk mengambil dan menyajikan sumber informasi web (Sibero, 2011). Web browser jenisnya banyak yang masing-masing mempunyai kelebihan dan kekurangan. Web browser juga menyesuaikan dengan sistem operasi yang digunakan komputer, seperti untuk dijalankan di operating sistem Windows, Linux dan bisa berjalan di sistem operasi mobile. Tentu keperluan dan perfomanya juga berbeda misalnya untuk sistem operasi yang berjalan pada mobile device maka kapasitasnya kecil dari sistem operasi yang berjalan pada PC (Purnama, 2016). Web browser dengan GUI (Graphical User Interface) berkembang cepat. Dengan GUI memudahkan pemakai melakukan point and click untuk pidah antar dokumen. Web browser GUI yang populer yaitu Mozilla Firefox, Internet Explorer, Netscape Navigator dan Opera (Kustiyahningsih \& Devie Rosa Anamisa, 2011). 


\section{Web Server}

Web Server merupakan perangkat lunak yang khusus bertugas melayani permintaanpermintaan dari browser akan dokumen-dokumen yang tersimpan didalamnya. Contoh IIS (Internet Information Services), PWS (Personal Web Server), dan Apache (Prasetyo, 2008). Web server adalah program aplikasi yang memililki fungsi sebagai tempat menyimpan dokumen-dokumen web (M. Rudyanto Arief, 2011). Sedangkan menurut Sibero (2011) dijelaskan bahwa "Web server adalah sebuah komputer yang terdiri dari perangkat keras dan perangkat lunak".

\section{METODE PENELITIAN}

Dalam memperoleh data sebagai sumber dasar penyusunan penelitian ini, metode penelitian yang digunakan ada dua metode, yaitu:

1. Metode Pengumpulan Data

Metode pengumpulan data yang digunakan dalam melakukan pengumpulan data untuk pembuatan penelitian ini adalah :

a. Wawancara, dilakukan dengan Kepala Puskesmas dan staff fungsional di UPTD Puskesmas Nanggulan Kulon Progo. Wawancara dilakukan untuk memperoleh informasi dan data yang digunakan dalam penelitian ini. Selain itu wawancara juga bertujuan untuk mengetahui kebutuhan sistem dalam pembuatan aplikasi "Sipedi" pada UPTD Puskesmas Nanggulan.

b. Observasi. Melakukan pengamatan langsung terhadap buku-buku dan yang ada di UPTD Puskesmas Nanggulan Kulon Progo. Observasi dilakukan untuk mengetahui kebutuhan informasi yang akan disimpan dalam bentuk digital.

c. Studi Pustaka, dilakukan dengan mencari referensi yang berhubungan dengan perancangan aplikasi "Sipedi". Selain itu juga mempelajari sumber data dan sistem informasi dari perpustakaan digital baik dari buku ataupun internet.

\section{Metode Pengembangan Perangkat Lunak}

Metode yang digunakan pada pengembangan perangkat lunak ini menggunakan model waterfall (Sukamto \& Shalahuddin, 2014) yang terbagi menjadi lima tahapan, yaitu:
a. Analisis Kebutuhan Perangkat Lunak
b. Desain
c. Pembuatan Kode Program
d. Pengujian
e. Pendukung (support) atau Pemeliharaan (maintenance)

Pada tahapan yang pertama metode pengembangan perangkat lunak yaitu analisa kebutuhan perangkat lunak dilakukan analisa kebutuhan, dalam pembuatan aplikasi "Sipedi" ini apa saja yang dibutuhkan baik berupa kebutuhan fungsional maupun kebutuhan non fungsional. Analisa kebutuhan fungsional dan nonfungsional dibahas pada pembahasan berikutnya. Tahapan kedua yaitu desain sistem merupakan hasil dari analisa kebutuhan yang kemudian di gambarkan dalam rancangan database, rancangan tampilan maupun rancangan sistem lainnya untuk di kerjakan di tahapan selanjutnya. Pada tahap ini akan menentukan bagaimana pembagunan sistem nantinya berjalan. Setelah di dapatkan rancangan dari aplikasi tahap selanjutnya yaitu menuangkan hasih desain sistem tersebut kedalam bentuk koding.

Pada tahapan pembuatan kode program akan dihasilkan rancang bangun aplikasi "Sipedi" yang akan di uji pada tahapan selanjutnya. Tahapan selanjutnya setelah di hasilkan implementasi 
koding adalah testing program. Setelah itu rancangan program yang sudah di buat di uji kehandalannya berdasarkan fungsi -fungsi yang telah di buat sebelumnya. Pengujian ini seringkali di kenal dengan Pengujian Black Box Testing. Pada tahapan ini sistem akan di uji dengan cara di berikan masukan data yang salah dan masukan data yang benar untuk mengetahui apakah ada kekurangan yang harus di perbaiki atau tidak.

Karena pada penelitian ini hanya sampai pada rancang bangun maka tahapan implementasi dan maintenance belum di lakukan.

\section{HASIL DAN PEMBAHASAN}

1. Analisis Kebutuhan Sistem

Analisis sistem merupakan tahapan awal mengembangkan sebuah sistem. Kebutuhan sistem bisa diartikan pernyataan tentang apa yang harus dikerjakan oleh sistem dan tentang karakteristik yang harus dimiliki sistem. Analisis kebutuhan sistem dapat dibagi menjadi dua yaitu analisis kebutuhan fungsional dan nonfungsional (Fatta, 2007).

a. Analisa Kebutuhan Fungsional

Kebutuhan Admin (Admin dapat login, menambah dan menghapus file ebook, menambah dan menghapus file jurnal, menghapus file buku tamu, memblokir dan mengaktifkan member dan menambah, mengubah dan menghapus file informasi).

- Kebutuhan User (User dapat melihat tampilan website meliputi home dan informasi dan mendaftar sebagai member dengan melakukan registrasi).

- Kebutuhan Member (Member dapat login ke halaman member, membaca dan download ebook, membaca dan download jurnal, melihat informasi)

b. Analisis Kebutuhan Non-Fungsional

Analisis kebutuhan non-fungsional bertujuan untuk mengetahui spesifikasi kebutuhan nonfungsional

a. Operasional

1) Komputer atau laptop dengan Sistem Operasi Windows 7;

2) Web browser seperti Mozila Firefox, Google Chrome, Internet Explorer, dan Opera.

b. Security

1) Sistem dilengkapi dengan keamanan, untuk mengakses ke halaman administrator, admin login terlebih dahulu dengan memasukkan username dan password;

2) Sistem dilengkapi login member, untuk masuk halaman member, harus registrasi menjadi member terlebih dahulu;

3) Password untuk admin dan member dienkripsi (md5) untuk mengamankan dari hacker;

4) Menu login Admin dibuat terpisah dari user dan member untuk mengamankan dari percobaan login selain admin.

c. Informasi

1) Memberikan informasi apabila username dan password yang dimasukkan salah;

2) Memberikan informasi apabila input yang dimasukkan masih kosong atau tidak sesuai dengan yang diminta sistem; 
3) Memberikan informasi apabila berhasil registrsasi menjadi member, format email yang dimasukkan salah, berhasil menghapus data, berhasil merubah data dan berhasil menyimpan data)

2. Rancangan Antar Muka

Menjelaskan rancangan antar muka yang terdapat pada aplikasi "Sipedi" UPTD Puskesmas Nanggulan, yang terdiri dari halaman untuk user, member dan admin.

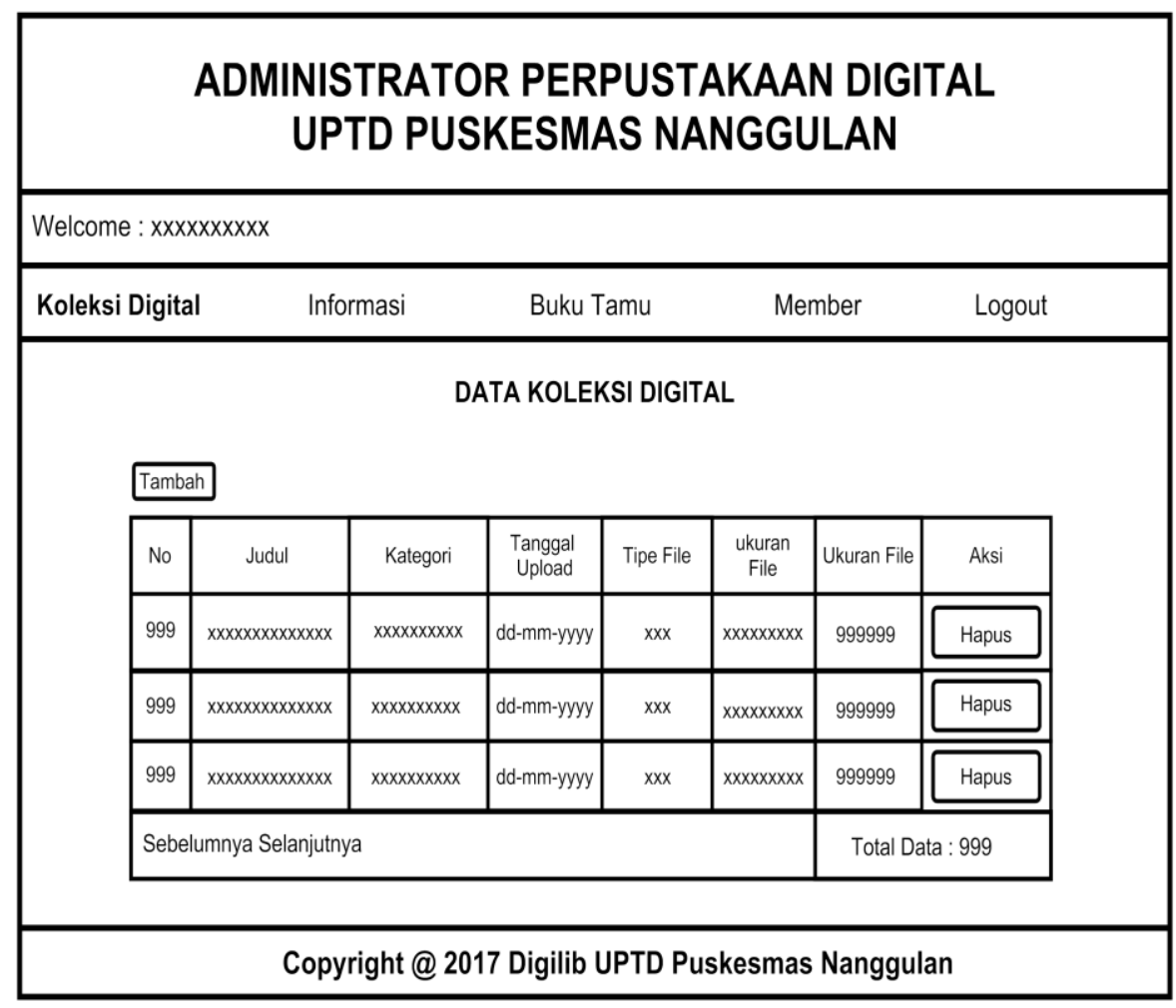

Gambar 1. Rancangan Antar Muka Halaman Home Admin

a. Rancangan Basis Data

Rancangan basis data menghasilkan pemetaan tabel-tabel yang digambarkan dengan Entity Relationship Diagram (ERD) dan Logical Relationship (LRS). Berikut rancangan basis data yang digunakan dalam penelitian ini : 
IJSE - Indonesian Journal on Software Engineering, Vol.5, No. 2, Desember 2019, 13-21 pISSN: 2461-0690 I elSSN: 2714-9935

Entity Relationship Diagram (ERD)

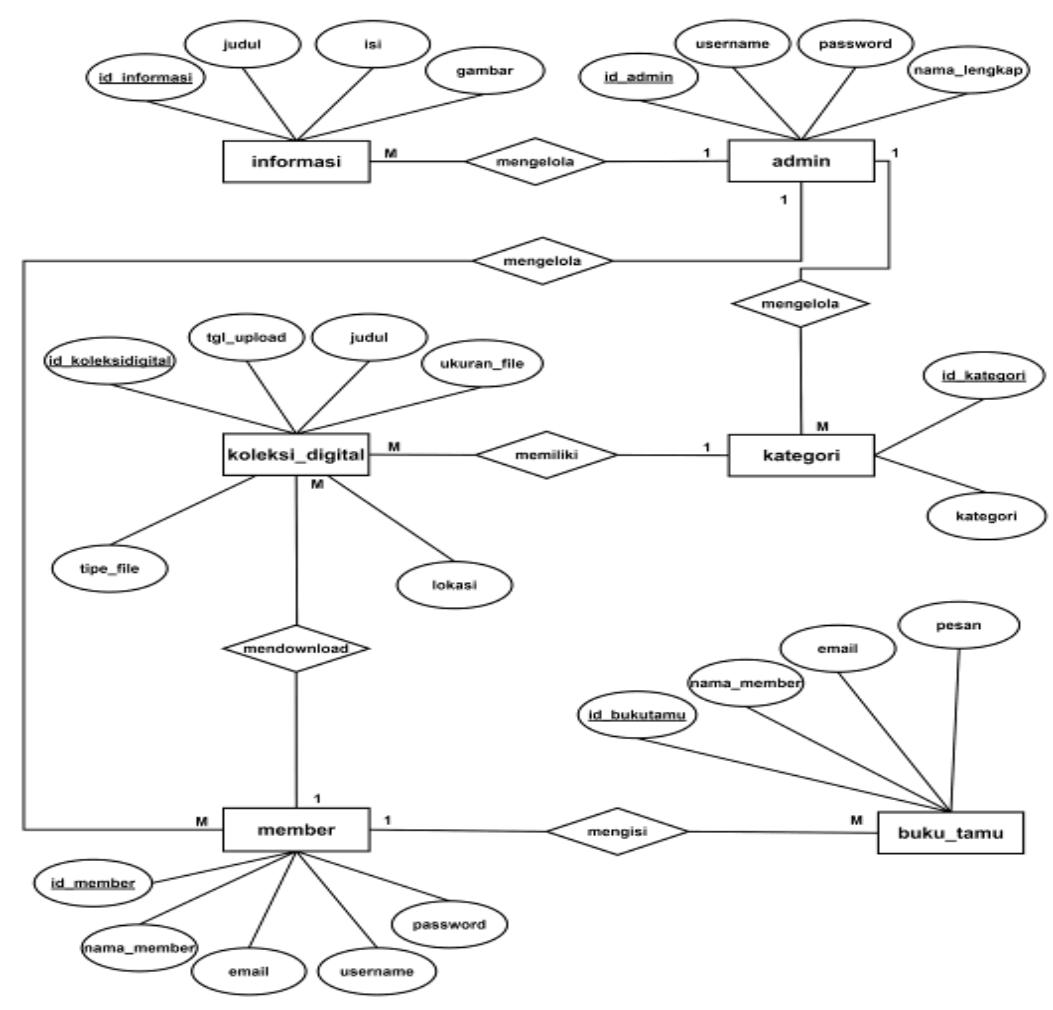

Gambar 2. Entity Relationship Diagram (ERD)

Logical Relation Structure (LRS)

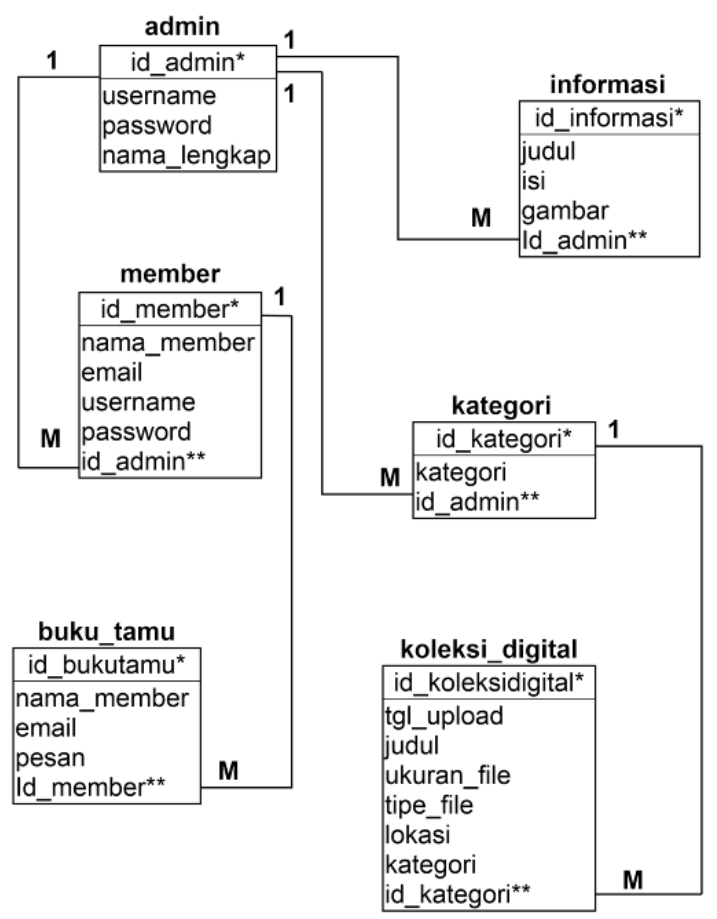

Gambar 3. Logical Relation Structure (LRS)

ejournal.bsi.ac.id/ejurnal/index.php/ijse Copyright @ $@$ Universitas Bina Sarana Informatika 
3. Implementasi

Berdasarkan rancangan yang telah dibuat, selanjutnya rancangan diimplementasikan.

a) Halaman index user merupakan halaman yang muncul ketika user. mengakses website Perpustakaan Digital UPTD Puskesmas Nanggulan. Halaman ini menampilkan menu yang dapat dipilih user.

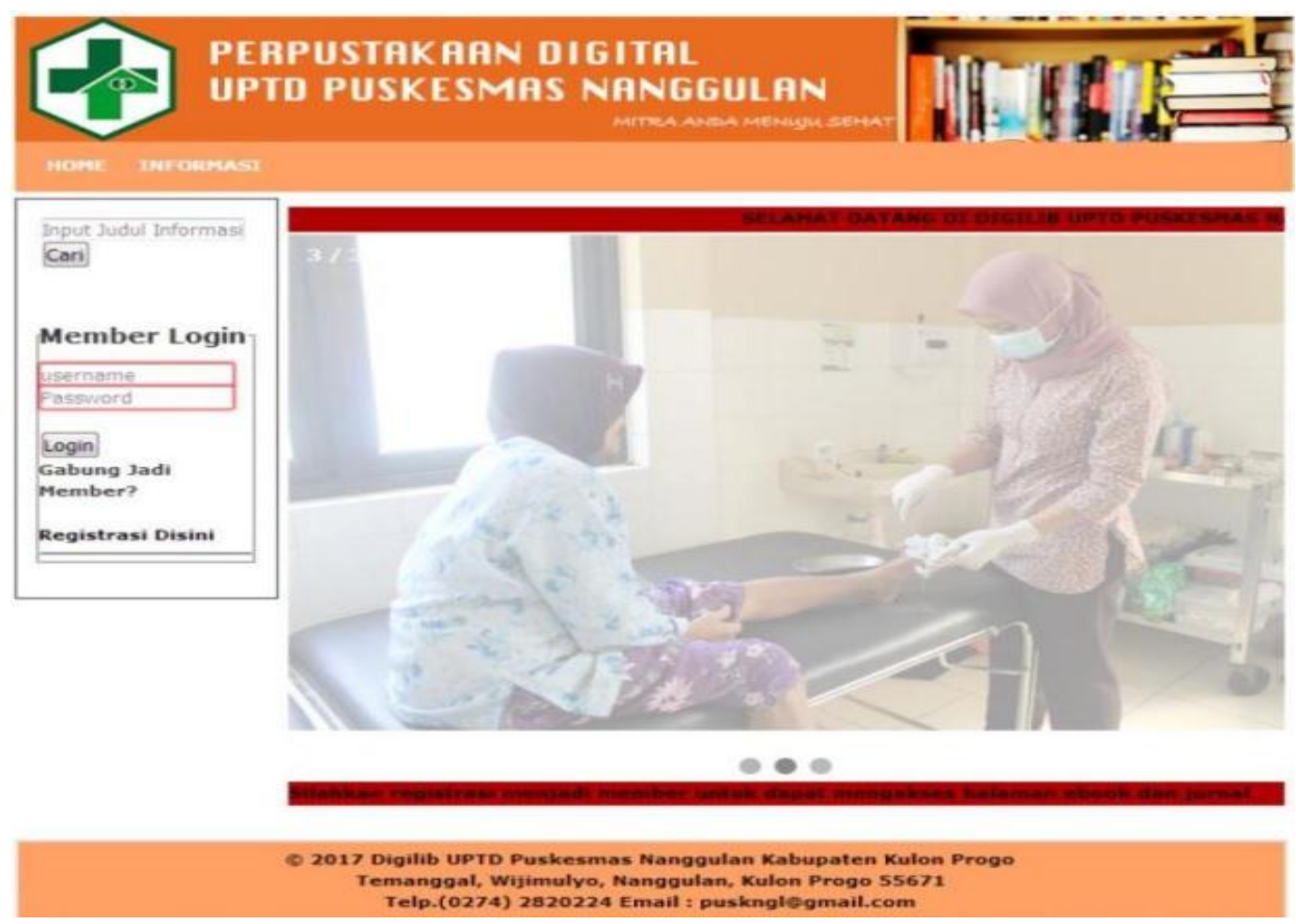

Gambar 5. Halaman index user 
b) Halaman koleksi digital menampilkan data koleksi digital yang berupa ebook dan jurnal. Halaman ini juga sebagai halaman pertama yang muncul setelah admin berhasil login. Pada halaman ini admin dapat mengelola data koleksi digital meliputi hapus dan tambah informasi.

\begin{tabular}{|c|c|c|c|c|c|c|}
\hline \multicolumn{7}{|c|}{$\begin{array}{c}\text { ADMINISTRATOR PERPUSTAKAAN DIGITAL } \\
\text { UPTD PUSKESMAS NANGGULAN }\end{array}$} \\
\hline \multicolumn{7}{|c|}{ Welcome : Budi Khoiruddin } \\
\hline \multicolumn{3}{|c|}{ Koleksi ogital } & \multicolumn{2}{|l|}{ Baxp Tams } & Nomber & Logout \\
\hline \multicolumn{7}{|c|}{ Data Koleksi Digital } \\
\hline \multicolumn{7}{|c|}{ rom } \\
\hline No. & Juduil & Kategon & Tanggalupioad & Tipe File & Ukuran File & Aksi \\
\hline 1 & Rencana Strategis Kementrian Kesehatan & ebook & $2017-08-10$ & pdt & 1865588 & Hapus \\
\hline 2 & $\begin{array}{l}\text { Status Gizi lbu Hami Serta Pengaruhnya } \\
\text { Terhadap Bayl Yang Dilanirkan }\end{array}$ & jurnal & $2017-08-10$ & pdf & 97424 & Hapus \\
\hline \multicolumn{7}{|c|}{\begin{tabular}{|l|l} 
Sebelumnya Selanutnya & Total Data: $\mathbf{2}$
\end{tabular}} \\
\hline \multicolumn{7}{|c|}{ Copyright @ 2017 Digilib UPTD Puskesmas Nanggulan } \\
\hline
\end{tabular}

Gambar 6. Halaman koleksi digital

4. Pengujian Unit

Pengujian unit dilakukan dengan metode Black Box testing. Hasil Pengujian Halaman Koleksi Digital adalah sebagai berikut :

Tabel1. Pengujian Black Box Testing Halaman Koleksi Digital

\begin{tabular}{|c|c|c|c|c|c|}
\hline No & $\begin{array}{l}\text { Skenario } \\
\text { Pengujian }\end{array}$ & Test Case & Hasil Yang diharapkan & $\begin{array}{c}\text { Hasil } \\
\text { Penguijan }\end{array}$ & Kesimpulan \\
\hline 1 & $\begin{array}{l}\text { Semua form } \\
\text { tidak diisi } \\
\text { kemudian klik } \\
\text { upload }\end{array}$ & $\begin{array}{l}\text { Tidak } \\
\text { mengisi } \\
\text { semua form }\end{array}$ & $\begin{array}{l}\text { Sistem menolak akses } \\
\text { dan tampil pesan "please } \\
\text { fill out this field" }\end{array}$ & $\begin{array}{l}\text { Sesuai } \\
\text { Harapan }\end{array}$ & Valid \\
\hline 2 & $\begin{array}{l}\text { Semua form diisi } \\
\text { dan salah satu } \\
\text { dikosongkan } \\
\text { kemudian klik } \\
\text { upload }\end{array}$ & $\begin{array}{l}\text { Nama file } \\
\text { (kosong) } \\
\text { Form } \\
\text { lainnya diisi } \\
\text { semua }\end{array}$ & $\begin{array}{l}\text { Sistem menolak akses } \\
\text { dan tampil pesan "please } \\
\text { fill out this field" }\end{array}$ & $\begin{array}{l}\text { Sesuai } \\
\text { Harapan }\end{array}$ & Valid \\
\hline 3 & $\begin{array}{l}\text { Semua form diisi } \\
\text { kemudian klik } \\
\text { upload }\end{array}$ & $\begin{array}{l}\text { Isi semua } \\
\text { form yang } \\
\text { tersedia }\end{array}$ & $\begin{array}{l}\text { Sistem menyimpan data } \\
\text { dan tampil } \\
\text { pesan“SUCCES: File } \\
\text { berhasil di upload }\end{array}$ & $\begin{array}{l}\text { Sesuai } \\
\text { Harapan }\end{array}$ & Valid \\
\hline 4 & $\begin{array}{l}\text { Menghapus data } \\
\text { koleksi digital }\end{array}$ & Klik hapus & $\begin{array}{l}\text { Tampil pesan " Anda } \\
\text { Yakin Akan Menghapus } \\
\text { Item Ini? “. Jika klik Ok } \\
\text { maka data terhapus dan } \\
\text { tampil pesan “ Berhasil! } \\
\text { Data Sudah Di Hapus. } \\
\text { Jika klik cancel maka } \\
\text { kembali ke halaman data } \\
\text { koleksi digital }\end{array}$ & $\begin{array}{l}\text { Sesuai } \\
\text { Harapan }\end{array}$ & Valid \\
\hline
\end{tabular}




\section{E. KESIMPULAN}

Berdasarkan pembahasan pada bab-bab sebelumnya yang telah diuraikan, maka penulis dapat mengambil kesimpulan, yaitu : aplikasi "Sipedi" sistem informasi perpustakaan digital berbasis web yang dirancang dapat mempermudah dalam penyampaiaan ilmu pengetahuan dan informasi khususnya di bidang kesehatan kepada masyarakat; aplikasi sudah dapat membantu masyarakat untuk memperoleh pengetahuan kesehatan berupa ebook dan jurnal yang dapat didownload setelah menjadi member; aplikasi yang dihasilkan dapat mempermudah petugas Puskesmas dalam menyampaikan informasi dan ilmu pengetahuan kesehatan kepada masyarakat.

Aplikasi yang telah dirancang masih jauh dari sempurna. Dalam rangka memberikan pelayanan yang lebih baik untuk kemudahan pelayanan ilmu pengetahuan dan informasi kepada seluruh masyarakat. Saran perbaikan dan peningkatan untuk mengembangan aplikasi "Sipedi" UPTD Puskesmas Nanggulan Kulon Progo agar lebih baik lagi, yaitu untuk mewujudkan interaksi masyarakat dengan petugas puskesmas dapat berjalan dengan baik sebaiknya ditambah fasilitas tanya jawab mengenai kesehatan, yang bisa berupa live chat atau forum komunikasi; lebih baik lagi jika ditambahkan menu mengubah password untuk admin dan member serta menu untuk menambah admin; demi menjaga dari kehilangan data yang tidak diinginkan sebaiknya ditambah fasilitas backup data.

\section{REFERENSI}

Badan Pusat Statistik. (2016). Provinsi Daerah Istimewa Yogyakarta Dalam Angka 2015. Yogyakarta.

Fatta, H. Al. (2007). Analisis dan Perancangan System Informasi untuk Keunggulan Perusahaan dan Organisasi Kelas Dunia. Yogyakarta: Andi Offset.

Hasugian, J. (2009). Dasar-Dasar Ilmu Perpustakaan dan Informasi. Medan: USU Press.

Kustiyahningsih, Y., \& Devie Rosa Anamisa. (2011). Pemrograman Basis Data Berbasis Web Menggunakan PHP \& MySQL. Yogyakarta: Graha Ilmu.

M. Rudyanto Arief. (2011). Pemrograman Web Dinamis Menggunakan PHP \& MySQL. Yogyakarta: Penerbit ANDI.

Prasetyo, E. (2008). Pemrograman Web PHP \& MySQL untuk Sistem Informasi Perpustakaan. Yogyakarta: Graha IImu.

Purnama, B. E. (2016). Konsep Dasar Internet. Yogyakarta: Teknosan.

Puspitosari, H. A. (2010). Membangun Website Interaktif dengan Adobe Creative Suite5 Tingkat Dasar. Yogyakarta: Scripta Media Creative.

Saleh, A. R. (2010). Membangun Perpustakaan Digital: Step by Step. Jakarta: Sagung Seta.

Sibero, A. F. K. (2011). Kitab Suci Web Programming. Yogyakarta: Mediakom.

Simarmata, J. (2010). Rekayasa Web. Yogyakarta: Penerbit ANDI.

Sukamto, R. A., \& Shalahuddin, M. (2014). Rekayasa Perangkat Lunak Terstuktur dari Berorientasi Objek. Bandung: Informatika.

Yuhefizar. (2013). Cara Mudah dan Murah Membangun dan Mengelola Website. Yogyakarta: Graha IImu. 